Vol. 1 | No. 1 | Januari 2020 | Hal. 23 - 28

\title{
MAKSIMALISASI HASIL PANEN KOPI MELALUI PEMANGKASAN CABANG PASCA PANEN DAN PENGENDALIAN HAMA SECARA ALAMI UNTUK MENINGKATKAN PRODUKSI KOPI
}

\author{
Rois Arifin \\ Fakultas Ekonomi dan Bisnis, Universitas Islam Malang \\ email: roisarifin_fe@unisma.ac.id
}

\begin{abstract}
ABSTRAK
Kopi (Coffea sp.) merupakan salah satu komoditas unggulan dalam sektor perkebunan Indonesia. Kopi secara umum dibagi menjadi dua jenis yang dihasilkan di Indonesia, yaitu kopi robusta dan kopi arabika. Total produksi kopi di Indonesia mulai dari tahun 2011 hingga 2015 selalu menurun. Peningkatan produktivitas dan mutu hasil kopi dapat dilakukan dengan cara memperhatikan teknik budidaya tanaman kopi mulai dari penanaman hingga perawatan. Metode pelaksaanan yang dilakukan pada saat observasi lapang. Dari hasil observasi dan praktek yang dilakukan dilapang didapatkan hasil teknik pemangkasan cabang kopi yang baik dan benar. Beberepa pemangkasan yang dilakukan oleh salah satu petani kopi diantaranya: (1) Pemangkasan cabang balik, (2) Pemangkasan cabang air, (3) Pemangkasan cabang rambut, (4) Pemangkasan cabang sakit, dan (5) Pemangkasan cabang produksi. Hama dan penyakit yang menyerang pada tanaman kopi yang paling banyak di jumpai di lapangan adalah uret/embuk. Hama ini menyerang pada bagian akar pada tanaman kopi dan uret ini membuat lubang-lubang pada tanaman akar kopi yang di serangnya. Pemangkasan cabang kopi sangat berperan penting dalam peningkatan produksi buah kopi, dan Pengendalian hama penyakit yang dilakukan oleh petani masih lebih mengutamakan pengendalian secara alami dan pengendalian secara kimia digunakan sebagai alternatif terakhir. Sebaiknya para petani kopi lebih banyak menggali informasi dalam teknik budidaya kopi yang benar dan baik, agar para petani kopi dapat meningkatkan hasil produksi kopi.
\end{abstract}

Kata Kunci: pemangkasan; cabang kopi; hama penyakit.

\section{PENDAHULUAN}

Kopi (Coffea sp.) merupakan salah satu komoditas unggulan dalam sektor perkebunan Indonesia. Kopi secara umum dibagi menjadi dua jenis yang dihasilkan di Indonesia, yaitu kopi robusta dan kopi arabika. Kopi jenis arabika dapat tumbuh dengan baik didaerah yang memiliki ketinggian diatas 1.000 - 2.100 meter di atas permukaan laut, sedangkan kopi robusta dapat tumbuh di ketinggian yang lebih rendah dari pada ketinggian penanaman kopi arabika, yaitu pada ketinggian 400-800m di atas permukaan laut. Kopi di Indonesia memiliki luas areal perkebunan yang mencapai 1,2 juta hektar. Dari luas areal tersebut, 96\% merupakan lahan perkebunan kopi rakyat dan sisanya 4\% milik perkebunan swasta dan Pemerintah. Asosiasi Eksportir dan Industri Kopi Indonesia (AEKI, 2015).

Total produksi kopi di Indonesia mulai dari tahun 2011 sebesar 638.646 ton yang kedua terbesar ada pada tahun 2012, yaitu sebesar 691.163 ton lalu setelah tahun 2012 tingkat produksi kopi mengalami penurunan. Penurunan produksi tersebut didasarkan oleh faktor cuaca dimana sering terjadi hujan. Namun pada tahun 2015 Indonesia kembali 
mampu meningkatkan produktivitas kopinya dengan total produksi yang mencapai 739.005 ton, jauh lebih besar daripada total produksi kopi tahun 2012 (Kementerian Pertanian, 2015). Selain itu faktor penurunan produksi dapat terjadi karena adanya pembaharuan pohon kopi, penggunaan pupuk yang berlebihan pada tahun sebelumnya, kemarau panjang, atau kesalahan pada pemotongan cabang kopi, sedangkan penurunan luas lahan dapat terjadi karena adanya alih fungsi lahan (Indreswari, 2015).

Peningkatan produktivitas dan mutu hasil kopi dapat dilakukan dengan cara memperhatikan teknik budidaya tanaman kopi mulai dari penanaman hingga perawatan. Kegiatan penanaman diawali dengan pemiliahan varietas yang sesuai dengan kondisi lahan, serta penentuan jarak tanam kopi yang disesuaikan dengan kemiringan tanah. Pemupukan dilakukan dengan memperhatikan waktu, dosis dan jenis pupuk serta cara pengaplikasiannya. Selain itu, perlu adanya pemangkasan agar tanaman kopi tetap rendah sehingga mudah dalam perawatan, pembentukan cabang-cabang produktif, mempermudah masuknya cahaya, serta mempermudah pengendalian hama dan penyakit (Prastowo, 2010).

Tujuan dari observasi lapang pada lahan kopi yaitu untuk mengetahui teknik budidaya tanaman kopi khususnya dalam teknik pemangkasan pada cabang tanaman kopi dan pengendalian hama yang dilakukan oleh petani serta membandingkan dengan teknik budidaya yang dijelaskan pada saat sosialisasi ekplorasi dan maksimalisasi produksi kopi.

Adapun manfaat dari observasi lapang yaitu dapat mengetahui teknik pemangkasan cabang kopi yang baik dan pengendalian hama sehingga diharapkan produksi kopi petani di Desa Wonoagung - Tirtoyudo menjadi optimal. Dengan peningkatan produksi tersebut dapat menigkatkan kesejahteraan bagi para petani kopi.

\section{METODE}

Metode pelaksaanan yang dilakukan pada saat observasi lapang meliputi (1) Partisipasi langsung yaitu dengan cara mengikuti pemangkasan cabang tanaman kopi, (2) Melakukan wawancara dan diskusi dengan pemilik lahan tentang cara pemangkasan cabang dan pengendalian hama serta kendala yang terjadi di lahan kopi. Kegiatan observasi lapang dilakukan pada hari Sabtu, tanggal 10 Agustus 2019 yang bertempat di salah satu lahan kelompok petani kopi di Desa Wonoagung, Kecamatan Tirtoyudo, Kabupaten Malang. Adapun alat dan bahan yang digunakan dalam observasi lapang yaitu gergaji dan gunting pertanian.

\section{HASIL DAN PEMBAHASAN}

\section{Teknik Pemangkasan Cabang Kopi}

Dari hasil observasi dan praktek yang dilakukan dilapang didapatkan hasil teknik pemangkasan cabang kopi yang baik dan benar. Adapun beberepa pemangkasan yang dilakukan oleh salah satu petani kopi diantaranya:

\section{a. Pemangkasan Cabang Balik}

Pemangkasan cabang balik perlu dilakukan karena apabila cabang tersebut tetap dibiarkan, maka daun pada cabang tersebut akan menutupi cabang lain dibawahnya sehingga cabang lain tidak mendapat sinar yang optimal dan dapat mempengaruhi produksi kopi. Pemangkasan ini dilakukan dengan cara memotong menggunakan gunting pertanian pada bagian cabang yang memiliki ciri berbalik arah dari arah pertumbuhan pada umumnya.

\section{b. Pemangkasan Cabang Air}

Pemangkasan cabang air dilakukan ketika pertumbuhan tanaman kopi dalam kondisi sehat. Karena cabang air merupakan tunas baru yang akan memunculkan 
cabang pada tanaman kopi, sehingga apabila pertumbuhan kopi dalam keadaan sehat maka cabang air perlu di pangkas untuk menghindari banyaknya cabang yang tidak berproduksi dan dapat mengurangi produksi karena hanya membentuk pertumbuhan vegetatif.

\section{c. Pemangkasan Cabang Rambut}

Pemangkasan rambut dilakukan dengan memotong cabang rambut pada tanaman kopi. Cabang rambut biasanya terdapat pada cabang-cabang kopi yang memiliki bentuk menyerupai rambut. Pemangkasan ini dilakukan agar tidak tumbuh menjadi banyak cabang yang tidak produksi.

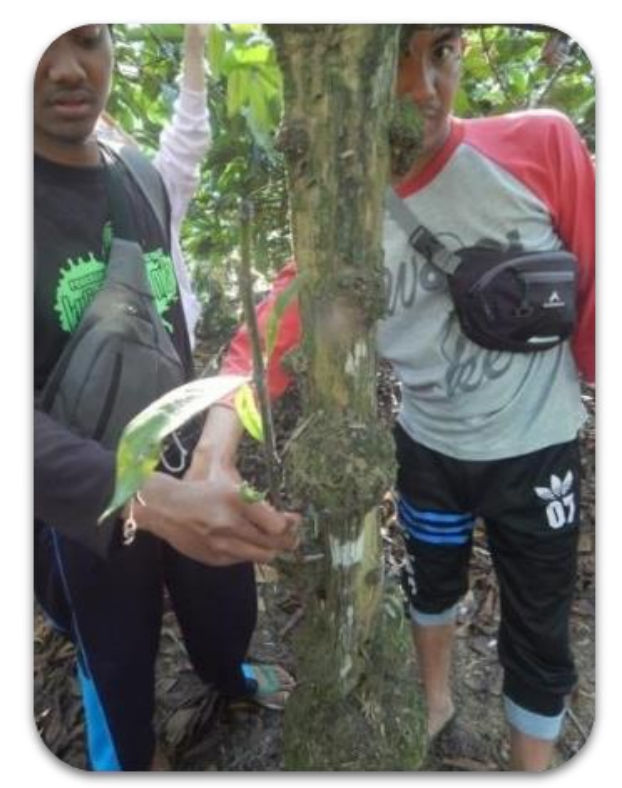

Gambar 1. Teknik pemangkasan cabang rambut

\section{d. Pemangkasan Cabang Sakit}

Pemangkasan cabang sakit dilakukan dengan memotong cabang yang memiliki ciri berdaun 1 atau 3, daun kering, dan daun berbintik. Cabang tersebut perlu dipangkas untuk menghindari penularan penyakit terhadap cabang yang lain, sehingga mempengaruhi produksi kopi.

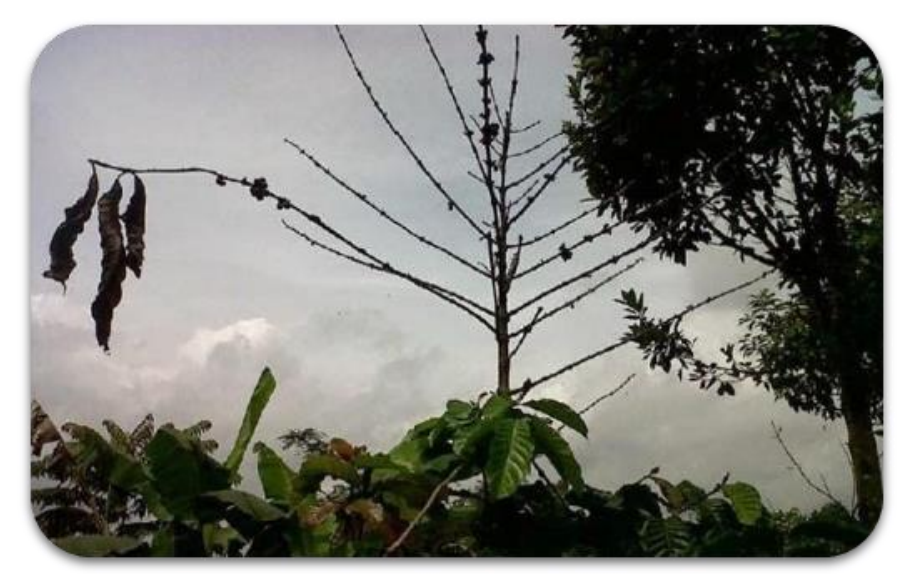

Gambar 2. Model cabang sakit 


\section{e. Pemangkasan Cabang Produksi}

Pemangkasan cabang produksi dilakukan untuk membentuk cabangcabang yang akan memunculkan buah. Adapun beberapa cabang produksi diantaranya:

$>$ b0: yaitu cabang yang akan berbuah tahun depan biasanya sebanyak 10 cabang.

> b1: yaitu cabang yang berbuah satu kali selama masa panen biasanya sebanyak 20 cabang.

$>$ b2: yaitu cabang yang berbuah dua kali selama masa panen banyaknya cabang 20 cabang.

$>$ b3: yaitu cabang yang berbuah tiga kali selama masa panen banyaknya cabang 10 cabang.

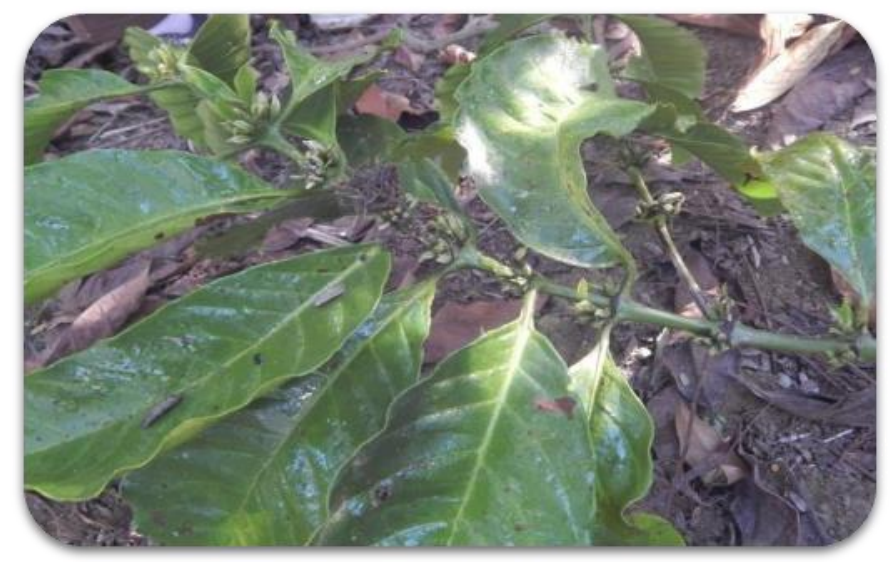

Gambar 3. Hasil pemangkasan cabang produksi

Jadi pemangkasan cabang produksi yaitu membentuk tajuk tanaman kopi khususnya cabang produksi dengan presentase masing-masing cabang produksi sebesar $60-80 \%$. Hal ini bertujuan untuk meningkatkan produksi buah kopi, karena apabila cabang terlalu banyak dan tidak berproduksi dapat mempengaruhi terhadap produksi buah kopi yang menyebabkan meningkatnya pertumbuhan vegetatif (daun) dari pada pertumbuhan generatif (buah).

\section{Pengendalian Hama dan Penyakit}

Hama dan penyakit yang menyerang pada tanaman kopi yang paling banyak di jumpai di lapangan adalah uret/embuk. Hama ini menyerang pada bagian akar pada tanaman kopi dan uret ini membuat lubang-lubang pada tanaman akar kopi yang di serangnya.

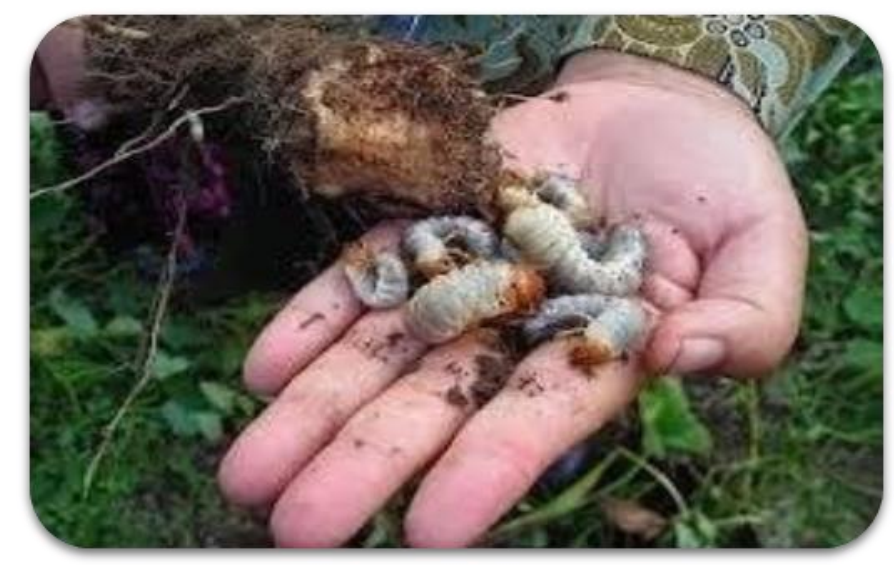

Gambar 4. Hama uret/embuk 
Uret yang masih muda memakan bagian-bagian akar yang lunak, tetapi kerusakan yang ditimbulkannya tidak begitu berarti. Semakin besar ukuran uret, jumlah makanan yang diperlukan akan semakin banyak sehingga kerusakan yang akan ditimbulkannya akan semakin besar. Uret dewasa dapat memakan kulit akar sampai habis. Adanya kerusakan akar ini dapat menyebabkan terjadinya kelayuan pada tanaman muda dan sering menimbulkan kematian. Pemberantasan biologis terhadap hama uret tidak begitu banyak dilakukan karena kurang efektif meskipun musuh-musuh alami dari uret cukup banyak. Dua macam cara pemberantasan yang banyak dilakukan adalah cara mekanis baik terhadap uret maupun terhadap kumbangnya pada waktu mengerjakan tanah atau pada waktu musim kumbang dan cara yang kedua adalah penggunaan insektisida.

Pengendalian yang dapat di lakukan untuk mengatasi hama uret ini ada dua yaitu pemberantasan mekanik dan pemberantasan kimiawi.

a. Pemberantasan mekanis Pengumpulan uret yang kemudian diikuti dengan pemusnahan dapat dilaksanakan pada waktu mengolah tanah. Bila penanaman hutan dengan cara tumpangsari maka sebaiknya tanah segera dikerjakan setelah panen. Stadium uret aktif umumnya berkisar antara 5 sampai 9 bulan sedangkan tanaman tumpang sari berumur antara 3-4 bulan hingga pada waku panen sebagian besar dari uret masih aktif dan masih berada di sekitar perakaran.

b. Pemberantasan kimiawi untuk mencegah/memberantas uret dengan menggunakan insektisida maka insektisida dicampur dengan tanah baik dalam bentuk larutan, embusan (dust) maupun butiran. Di daerah yang sering terjadi serangan hama uret, pecampuran insektisida dengan tanah harus dilakukan sebelum atau pada saat menanam dan jangan ditunggu sampai kerusakan oleh uret terjadi.

\section{KESIMPULAN}

Berdasarkan hasil observasi lapang disalah satu lahan milik petani kopi dapat disimpulkan bahwa (1) Pemangkasan cabang kopi sangat berperan penting dalam peningkatan produksi buah kopi, maka untuk itu diperlukan pengamatan terlebih dahulu sebelum melakukan pemangkasan. Karena apabila salah dalam melakukan pemangakasan maka akan mempengaruhi jumlah cabang yang berproduksi, (2) Pengendalian hama dan penyakit yang dilakukan oleh kebanyakan petani di Desa Wonoagung-Tirtoyudo masih lebih mengutamakan pengendalian secara alami dan pengendalian secara kimia digunakan sebagai alternatif terakhir, dan (3) Petani kopi di Desa Wonoagung-Tirtoyudo sudah menerapkan teknik pemangkasan yang disampaikan oleh pemateri pada saat sosialisasi peningkatan produksi kopi.

Penulis menyarankan dari hasil observasi lapang yang di lakukan sebaiknya para petani kopi lebih banyak menggali informasi dalam teknik budidaya kopi yang benar dan baik, agar para petani kopi dapat meningkatkan hasil produksi kopi serta diperlukan kemandirian petani dalam mengolah hasil produksi kopi hingga pasca panen.

\section{DAFTAR RUJUKAN}

AEKI. 2015. Asosiasi Eksportir dan Industri Kopi di Indonesia. http://aeki.aice.org. Diakses pada tanggal 30 Oktober 2017.

Anggara, Anies., Marini dan Sri. 2011. Kopi Si Hitam Menguntungkan: Budidaya dan Pemasaran. Yogyakarta: Penerbit Cahaya Atma Pustaka.

Anshori, M. Fuad. 2014. Analisis Keragaman Morfologi Koleksi Tanaman Kopi Arabika dan Robusta Balai Penelitian Tanaman Industri dan Penyegar Sukabumi. Fakultas Pertanian. Institut Pertanian Bogor. 
Arief, M dan Candra Wirawan. 2011. Panduan Sekolah Lapangan Budidaya Kopi Konservasi. Jakarta: Conservation International Indonesia.

Direktorat Jenderal Perkebunan. 2009. Volume dan nilai ekspor, impor Indonesia. http://Direktorat Jenderal Perkebunan.deptan.go.id. Diakses pada tanggal 30 Oktober 2017.

Ekadinata, 0. 2002. Peranan Uji Citarasa dalam Pengendalian Mutu Kopi. Materi Pelatihan Uji Citarasa Kopi. Jember: Pusat Penelitian Kopi dan Kakao.

Kementerian Pertanian. 2015. Basis Data Ekspor-Impor Komoditi Pertanian. http://www.pertanian.go.id. Diakses pada tanggal 30 Oktober 2017.

Najiyati, S dan Danarti. 2001. Kopi, Budidaya dan Penanganan Lepas Panen. Jakarta: Penebar Swadaya.

Najiyati, S dan Danarti. 2012. Kopi, Budidaya dan Penanganan Lepas Panen. PT. Jakarta: Penebar Swadaya.

Nasution, H. S. P. 2006. Prospek Tinggi Bertanam Kopi Pedoman Meningkatkan Kualitas Perkebunan Kopi. Yogyakarta: Pustaka Baru.

Ningtyas, I. Perkebunan Kopi Rakyat di Jawa Timur 1920-1942. J. Avatra, eJournalPendidikan Sejarah. 2(1): 122-129.

Panggabean, Edy. 2011. Buku Pintar Kopi. Jakarta Selatan: PT. Agro Media Pustaka. p. 124132.

Prastowo, Bambang, dkk. 2010. Budidaya dan Pasca Panen Kopi. Jakarta: Pusat Penelitian dan Pengembangan Perkebunan.p. 20-26.

Pusat Penelitian Kopi dan Kakao (Puslitkoka). 2006. Pedoman Teknis Tanaman Kopi. Jember: Budidaya dan Pasca Panen Kopi.

Rahardjo, Pudji. 2012. Panduan Budi Daya Pengelolaan Kopi Arabika dan Robusta. Jakarta: Penebar Swadaya.

Ryan dan Soemaro. 2016. Pengelolaan Lahan untuk Kebun Kopi. Malang: Penerbit Gunung Samudra. 